\title{
Pemberdayaan Perempuan melalui Pengembangan Usaha Minuman Tradisional Wedang Uwuh di Desa Muntuk, Dlingo, Bantul, Yogyakarta
}

\author{
Women's Empowerment through the Development of the Wedang Uwuh Traditional \\ Beverage Business in Muntuk Village, Dlingo, Bantul, Yogyakarta
}

Tanto Lailam ${ }^{*}$
Awang Daru Murti
1Department of Law, Universitas
Muhammadiyah Yogyakarta, Bantul,
Dearah Istimewa Yogyakarta,
Indonesia Munammadiyah
2Department of Governmental Studies,
Universitas
Yogyakarta, Bantul, Daerah Istimewa
Yogyakarta, Indonesia
*email: tanto.tatanegara@gmail.com
Kata Kunci
Wedang Uwuh
Pemberdayaan
Usaha

\begin{abstract}
Abstrak
Fokus pengabdian ini adalah pemberdayaan perempuan melalui pengembangan usaha minuman tradisional wedang uwuh. Wedang uwuh merupakan kuliner/jenis minuman tradisional yang cukup membumi di kalangan masyarakat Daerah Istimewa Yogyakarta. Wedang uwuh merupakan minuman disajikan panas atau hangat memiliki rasa manis dan pedas dengan warna merah cerah dan aroma harum. Pengabdian ini dilatarbelakangi beberapa persoalan, diantaranya bahwa usaha wedang uwuh belum memiliki ijin Produk Industri Rumah Tangga (PIRT), pengelola belum memahami bagaimana melakukan pemasaran dan membuat branding wedang uwuh, wedang uwuh belum memiliki packaging yang sesuai sasaran pasar pariwisata, dan lainnya. Untuk mengatasi persoalan tersebut, dalam pengabdian ini dilakukan berbagai kegiatan pengembangan usaha wedang uwuh, diantaranya upaya pengurusan ijin PIRT, pelatihan komunikasi pemasaran dan branding produk, pelatihan marketing via media sosial, pelatihan pengepakan wedang uwuh, dan fasilitasi alat pengembangan usaha dan packaging sesuai sasaran wisatawan.
\end{abstract}

\begin{abstract}
The focus of community service is the empowerment of women through the business development of wedang uwuh traditional beverage. Wedang uwuh is a traditional beverage that is famous among the people of the Special Region of Yogyakarta. Wedang uwuh is a hot or warm beverage that has a sweet and spicy taste with bright red and fragrant aroma. The problems motivate this community service, among others are the wedang uwuh business does not yet have a permit for household industrial products (PIRT), the manager does not understand how to market and make branding of wedang uwuh, wedang uwuh does not have packaging that fits the market target tourism, and others. To overcome this problem, in this service a variety of wedang uwuh business development activities were carried out, among others are efforts to manage PIRT permits, product marketing, and branding communication training, marketing training via social media, wedang uwuh packing training, and facilitation of business development tools and appropriate packaging tourist target
\end{abstract} (http://creativecommons.org/licenses/by-sa/4.0/). DOI: https://doi.org/10.33084/pengabdianmu.v4i2.802.

\section{PENDAHULUAN}

Desa Muntuk terletak di Kecamatan Dlingo Kabupaten Bantul Propinsi Daerah Istimewa Yogyakarta. Desa
Muntuk memiliki potensi kemandirian masyarakatyang sangat baik, karena berdekatan dengan wisata Puncak Pinus Becici, Pinus Asri, Negeri diatas awan Mangunan yang merupakan wisata unggulan Provinsi DIY. 
Pengembangan Desa Muntuk ini semakin cepat seiring agenda besar otonomi desa yang menjadi amanah Undang-Undang Republik Indonesia Nomor 6 Tahun 2014 tentang Desa serta Peraturan Pemerintah Republik Indonesia Nomor 47 Tahun 2015 tentang Perubahan Atas Peraturan Pemerintah Nomor 43 Tahun 2014 tentang Peraturan Pelaksanaaan Undang-undang Desa Nomor 6 Tahun 2014 tentang Desa.

Otonomi desa dimaknai sebagai adanya kemampuan serta prakarsa masyarakat desa untuk dapat mengatur dan melaksanakan dinamika kehidupannya dengan didasarkan pada kemampuannya sendiri (Mardhiah, 2017; Nakir, 2013). Secara sosiologis yang paling berperan dalam penyelenggaraan otonomi desa adalah struktur yang dibentuk oleh relasi antar warga (horisontal) dan antara warga dengan perangkat desa (vertikal) yang bersimpul pada Pemerintah Desa yang dipimpin oleh Kepala Desa/Lurah Desa (Zanibar, 2007). Intinya bahwa otonomi desa adalah sebuah agenda besar yang mengarahkan Desa Muntuk menjadi lebih demokratis, mandiri dan sejahtera.

Untuk itu, pembangunan desa dan pemberdayaan masyarakat desa berdasarkan prakarsa masyarakat sangat penting dilakukan. Dengan harapan dapat meningkatkan kesejahteraan masyarakat dan kualitas hidup manusia serta penanggulangan kemiskinan melalui pemenuhan kebutuhan dasar, pembangunan sarana dan prasarana desa, pengembangan potensi ekonomi lokal, serta pemanfaatan sumber daya alam dan lingkungan secara berkelanjutan (Surono, 2017; Oroh, 2014).

Salah satu usaha yang dikembangkan dalam upaya mewujudkan kemandirian adalah dibentuknya Peningkatan Peranan Wanita menuju Keluarga Sehat Sejahtera (P2W KSS) Desa Muntuk yang memiliki usaha berbagai macam kuliner, baik wedang uwuh, kripik pisang, kripik singkong, dan lainnya. Fokus pengabdian ini untuk pengembangan usaha wedang uwuh sebagai minuman tradisional yang digemari.

Wedang uwuh merupakan kuliner jenis minuman tradisional yang cukup membumi di kalangan Dusun Muntuk, bahkan di seluruh wilayah Daerah Istimewa Yogyakarta. Wedang uwuh merupakan minuman disajikan panas atau hangat memiliki rasa manis dan pedas dengan warna merah cerah dan aroma harum. Rasa pedas karena bahan jahe, sedangkan warna merah karena adanya secang (Munawaroh, 2014). Wedang uwuh produk Ibu-ibu Pembinaan Kesejahteraan Keluarga (PKK) sudah dalam bentuk kemasan, namun pemasaran wedang uwuh baru sebatas masyarakat sekitar. Tentu Potensi ini harus dikembangkan melalui pemasaran yang berdampak pada peningkatan usaha Ibu-ibu. Persoalannya adalah bahwa usaha wedang uwuh belum memiliki ijin Produk Industri Rumah Tangga (PIRT), pengelola belum memahami bagaimana melakukan pemasaran dan membuat branding wedang uwuh, dan peralatan pembuatan wedang uwuh yang belum mendukung produksi, wedang uwuh belum memiliki packaging yang sesuai sasaran pasar pariwisata, dan lainnya. Tujuan program pengabdian kepada masyarakat ini adalah menjadikan mitra sebagai model pertumbuhan ekonomi dan kesejahteraan masyarakat berkelanjutan melalui pengembangan usaha wedang uwuh, dimana khalayak yang menjadi sasaran dalam pengabdian ini adalah kelompok P2W KSS Desa Muntuk.

\section{METODOLOGI}

Metode pengabdian yang dilaksanakan lebih menekankan pada pemberdayaan masyarakat (partisipasi aktif) sebagai inti gerakannya, dengan menempatkan mitra sebagai pelaku utama pada setiap tahapan perencanaan, pelaksanaan, serta monitoring dan evaluasi program. Pendekatan pemberdayaan 
dalam pengabdian ini berprinsip pada kemandirian masyarakat, metode ini bertujuan untuk meningkatkan kapasitas masyarakat dan menguatkan perekonomian lokal (Zuliyah, 2010). Untuk pelaksanaan pengabdian ini dilakukan dengan beberapa metode yang digunakan:

\section{Pelatihan}

Metode pelatihan dilakukan untuk mengurangi persoalan sumber daya manusia dan pemasaran usaha masyarakat. Program-program pelatihan dalam pengabdian dikembangkan dengan metode yang sederhana, yaitu dengan menyelenggarakan sarasehan dan diskusi santai/informal. Selain itu, sharing pengalaman merupakan syarat untuk dapat meningkatkan kreativitas dan inovasi masyarakat dan menjadi penentu pelaksanaan kegiatan dalam menciptakan masyarakat yang mandiri kompetitif berdaya saing (Widjajanti, 2011). Metode pelatihan dengan diskusi informal bertujuan untuk mendorong partisipasi dan perhatian peserta yang lebih intens (Kusumasari \& Suyatna, 2015).

2. Pendampingan

Untuk memastikan bahwa program-program pelatihan dapat berkelanjutan, tim pengabdian juga melakukan kegiatan pendampingan secara rutin. Dalam proses pendampingan ini, tim pengabdi juga memberikan solusi-solusi atas hambatan yang dihadapi oleh masyarakat. Pendampingan ini dilakukan agar program dapat terlaksana dengan baik atau merupakan penerapan hasil pelatihan yang dilakukan (Andayani \& Afandi, 2016). Selain metode diatas, pengabdian juga dilakukan fasilitasi peralatan dan marketing dalam rangka pengembangan usaha.

\section{HASIL DAN PEMBAHASAN}

Minuman tradisional/lokal merupakan salah satu identitas suatu kelompok masyarakat yang sangat mudah untuk ditemukan dan mudah untuk dikenali. Setiap wilayah di Indonesia memiliki kekayaan kuliner yang menjadi ciri khas atau identitas daerah tersebut. Makanan/minuman tradisional atau kuliner lokal adalah produk makanan yang sering dikonsumsi oleh suatu kelompok masyarakat atau dihidangkan dalam perayaan dan waktu tertentu, diwariskan dari generasi ke generasi, dibuat sesuai dengan resep secara turuntemurun, dibuat tanpa atau dengan sedikit rekayasa, dan memiliki karakteristik tertentu yang membedakannya dengan kuliner daerah lain (Tyas, 2017). Minuman lokal khas daerah-daerah di Indonesia sudah ada sejak lama dan masih bertahan hingga saat ini sehingga sangat dihargai sebagai warisan budaya. Resep yang digunakan juga sudah diturunkan dari generasi ke generasi, bahkan cara mengolahnya juga masih melestarikan cara lama. Karena menjadi bagian dari suatu daerah, maka minuman tradisional ini sangat mudah ditemukan, bahkan menjadi ikon pariwisata di tempat tersebut (Munawaroh, 2014).

Minuman tradisional dapat dikatakan sebagai identitas lokal karena keberadaannya yang menjadi bagian dari budaya masyarakat, seperti tata cara tertentu dalam mengolah bahan makanannya, perannya dalam budaya masyarakat dan tata perayaan, serta resep yang terjaga secara turun-temurun. Identitas budaya merupakan kondisi dimana setiap individu menerima dan menghargai perbedaan dan kearifan lokal serta mengakui hak atas perbedaan. Orang yang memiliki identitas budaya yang kuat bersedia untuk menerima keberagaman budaya dan mampu untuk mengadakan kontak dengan budaya lain tanpa menghilangkan budayanya sendiri (Tyas, 2017).

Salah satu minuman khas Yogyakarta dan menjadi minuman lintas generasi adalah wedang uwuh. Wedang uwuh ini merupakan ramuan dengan rempah-rempah Indonesia, ramuan ini digandrungi masyarakat bahkan 
para wisatawan nusantara maupun wisatawan asing yang datang dari luar negeri. Dalam bahasa Jawa, wedang uwuh merupakan minuman dari berbagai macam ramuan baik berupa rempah-rempah, dedaunan dan kayu kecil. Aroma dan rasa dari wedang uwuh ini pun sangat khas dimana manis, pedas, wanginya rempah-rempah asli Indonesia berpadu menjadi satu (Munawaroh, 2014).

Bahan yang digunakan untuk membuatnya antara lain kayu secang, kayu manis, jahe, cengkeh, pala/daun, pala, akar sereh dan kapulaga. Dilihat dari bahan pembuatannya yang sangat alami, tentu bisa kita bayangkan manfaat dari minuman ini. Wedang uwuh memiliki manfaat yang dapat diperoleh jika kita mengonsumsi, diantaranya: menurunkan kolesterol, menghilangkan capek, menyegarkan badan, meningkatkan kekebalan tubuh, melancarkan sirkulasi darah, menyembuhkan dan mencegah masuk angin, menghangatkan badan, mengatasi sakit gigi, mengobati perut kembung, mengatasi sakit kepala, dan mengatasi obesitas (Munawaroh, 2014).

Pengembangan usaha wedang uwuh dilakukan dengan upaya pengurusan ijin PIRT, pelatihan komunikasi pemasaran dan branding produk, pelatihan marketing via media sosial, pelatihan pengepakan wedang uwuh, dan fasilitasi alat pengembangan usaha.

\section{Pengurusan Ijin PIRT}

Wedang uwuh sebagai salah satu usaha kuliner/industri makanan rumah tangga tentu harus mendapatkan sertifikat keamanan pangan, sebagai salah satu syarat mendapatkan legalitas pengakuan keamanan makanan dari Dinas Kesehatan Kabupaten Bantul berupa nomor PIRT. Nomor PIRT ini menjadi salah satu syarat bagi wedang uwuh untuk dijual di pasaran, sehingga dapat menguntungkan P2W KSS secara ekonomi (Wibowo \& Winarni, 2017). Dengan PIRT produk usaha wedang uwuh dapat dipasarkan ditempat-tempat wisata maupun swalayan.

Proses memperoleh PIRT membutuhkan waktu yang cukup lama, mulai dari pelatihan bagi pengelola, pengujian air ditempat pengelolaan hingga penyerahan ijin. Pelatihan bagi kelompok usaha sudah dilakukan oleh Dinas Kesehatan melalui kegiatan "Pelatihan Penyuluhan Keamanan Pangan". Kegiatan ini diikuti oleh kelompok usaha yang mengajukan permohonan untuk mendapatkan Sertifikat PIRT.

Berkaitan dengan wedang uwuh Muntuk telah melalui rangkaian tersebut, dan telah dikeluarkan hasil pemeriksanan sampel air dan dinyatakan layak, artinya wedang uwuh Muntuk tinggal menunggu penyerahan sertifikat PIRT.

2. Pelatihan Komunikasi Pemasaran dan Branding Wedang Uwuh

Pelatihan Komunikasi Pemasaran dan Branding Produk usaha ini menghadirkan dosen dan praktisi komunikasi Ibu Nita Andrianti, S.IP., M.A. dari Fakultas Komunikasi dan Multimedia Universitas Mercu Buana Yogyakarta. Tujuan pelatihan ini agar pengelola wedang uwuh kelompok P2W KSS memiliki pemahaman bagaimana memasarkan dan membuat branding wedang uwuh secara baik, sehingga dapat meningkatkan kualitas dan kuantitas produk wedang uwuh sekaligus meningkatkan kesejahteraan masyarakat Muntuk.

Pelatihan komunikasi pemasaran bagi usaha wedang uwuh diperlukan untuk menciptakan, mengkomunikasikan, mengenalkan dan menyampaikan produk wedang uwuh ke masyarakat. Komunikasi pemasaran (marketing communication) adalah sarana di mana kelompok usaha berusaha menginformasikan, membujuk, dan 
mengingatkan konsumen secara langsung maupun tidak langsung tentang wedang uwuh (Lestari, 2015). Dalam pelatihan ini langsung dilakukan praktek oleh pengelola usaha wedang uwuh, dengan menggunakan media sosial sebagai media komunikasi pemasaran. Dokumentasi proses pelatihan komunikasi pemasaran disajikan pada Gambar 1.

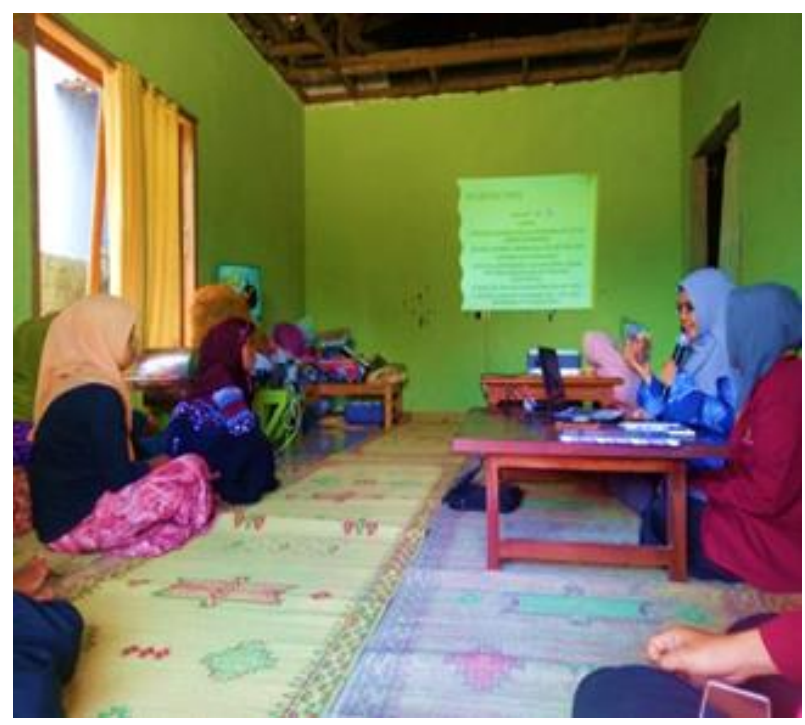

Gambar 1. Pelatihan Komunikasi Pemasaran dan Branding Produk.

\section{Pelatihan Pengepakan Wedang Uwuh}

Sebagai bagian proses untuk komunikasi pemasaran adalah pembungkusan atau packaging yang baik untuk meningkatkan kualitas dan kuantitas produk wedang uwuh. Untuk itu dilakukan pelatihan pengepakan wedang uwuh yang diikuti oleh sebagian besar pengelola/lbu-ibu P2W KSS. Pelatihan ini dilakukan agar wedang uwuh yang diproduksi lebih higienis dan bermutu, dan pengemasan dan penyimpanan yang sesuai dengan standar produk usaha. Dokumentasi pelatihan pengepakan disajikan pada Gambar 2.

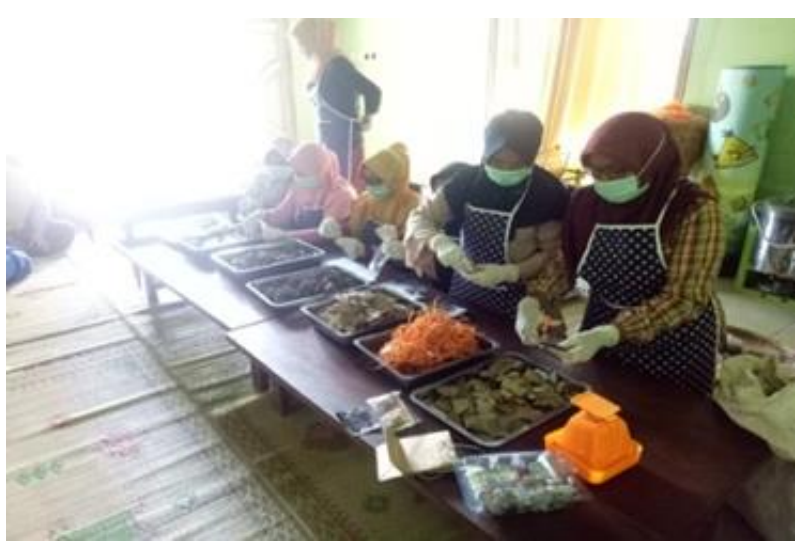

Gambar 2. Pelatihan Pengepakan Wedang Uwuh.

4. Fasilitasi Peralatan Usaha Kuliner

Untuk meningkatkan produksi wedang uwuh tentu dibutuhkan alat-alat yang mendukung peningkatan produksi, hal ini untuk memberikan solusi terbatasnya peralatan wedang uwuh yang dimiliki P2W KSS. Untuk itu sesuai kebutuhan diberikan bantuan alat-alat produksi untuk menunjang usaha, meliputi: kompor gas dan selang, oven kompor, alat pemotong, dan lainnya. Selain memberikan fasilitasi tersebut, dalam pengabdian ini juga diberikan fasilitasi packaging wedang uwuh yang sesuai dengan minat pariwisata. Dokumentasi pemberian peralatan produksi disajikan pada Gambar 3.

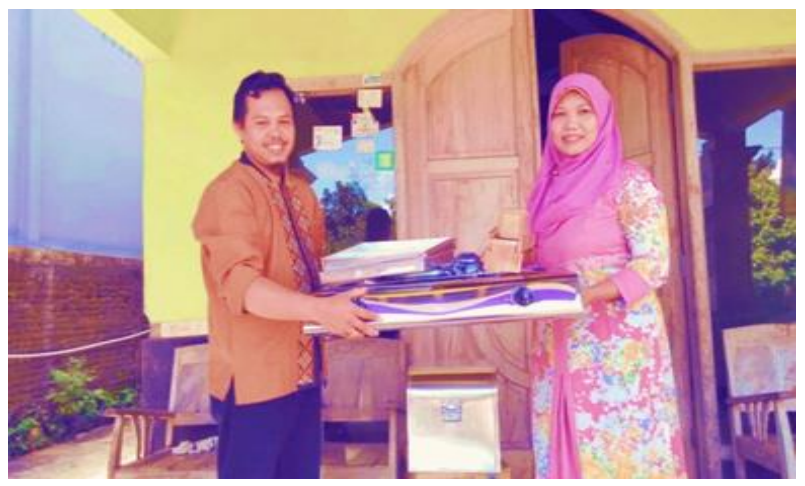

Gambar 3. Pemberian Peralatan Produksi kepada Perwakilan P2W KSS.

\section{KESIMPULAN}

Wedang uwuh sebagai minuman tradisional khas Yogyakarta dan banyak diminati oleh masyarakat, wisatawan nusantara dan wisatawan asing perlu 
dikembangkan secara baik dan mandiri. Untuk mewujudkan usaha mandiri dan mensejahterakan rakyat tersebut telah dilakukan pengabdian, diantaranya upaya pengurusan ijin PIRT, pelatihan komunikasi pemasaran dan branding produk, pelatihan marketing via media sosial, pelatihan pengepakan wedang uwuh, dan fasilitasi alat pengembangan usaha dan packaging sesuai sasaran wisatawan. Kedepan diperlukan pengelolaan usaha wedang uwuh yang lebih profesional dan berbasis kekinian (perkembangan teknologi informasi), serta pelu dilakukan peningkatan kualitas dan kuantitas (misalnya dilakukan pengemasan/ wedang uwuh celup).

\section{UCAPAN TERIMA KASIH}

Dengan berakhir dan berhasilnya program pengabdian ini, penulis mengucapkan terima kasih kepada Lembaga Penelitian, Publikasi \& Pengabdian Masyarakat Universitas Muhammadiyah Yogyakarta, Mitra masyarakat Kelompok P2W KSS Desa Muntuk, serta Kelompok Kuliah Kerja Nyata (KKN) Universitas Muhammadiyah Yogyakarta 004 Dusun Muntuk, Desa Muntuk Dlingo Bantul atas segala bantuan dan dukungannya dalam pelaksanaan kegiatan Pengabdian kepada masyarakat ini.

\section{REFERENSI}

Andayani, Afandi, M. 2016. Pemberdayaan dan Pendampingan Komunitas Penyandang Disabilitas dalam Mengakses Pendidikan Tinggi. Aplikasia: Jurnal Aplikasi Ilmu-Ilmu Agama. 16(2):153-166.

Kusumasari, B., Suyatna, H. 2015. Peningkatan Kapabilitas Pemasaran Pascabencana Bagi Perempuan Hunian Tetap Pager Jurang, Sleman, Yogyakarta. Jurnal Pengabdian Kepada Masyarakat (Indonesian Journal of Community Engagement). 1(1):14-23. https://doi.org/10.22146/jpkm.16925
Lestari, S.P. 2015. Hubungan Komunikasi Pemasaran dan Promosi Dengan Keputusan Memilih Jasa Layanan Kesehatan (Studi Pada Rumah Sakit Islam Lumajang). Interaksi: Jurnal Ilmu Komunikasi. 4(2):139-147. https://doi.org/10.14710/interaksi.4.2.139147

Mardhiah, N. 2017. Identifikasi Tujuan dan Sasaran Pembangunan Desa Kabupaten Aceh Barat. Jurnal Public Policy. 3(1):77-88. https://doi.org/10.35308/jpp.v3i1.753

Munawaroh, S. 2014. Wedang Uwuh sebagai Ikon Kuliner Khas Imogiri Bantul. Jantra. 9(1):69-79.

Nakir, S. 2013. Otonomi Daerah dan Desentralisasi Desa: Menuju Pemberdayaan Masyarakat Desa. Jurnal Politik Profetik. 1(1):1-21. https://doi.org/10.24252/jpp.v1i1.1621

Oroh, G.S. 2014. Peranan Pemerintah Desa dalam Pemberdayaan Masyarakat di Bidang Pertanian di Desa Tumaratas Kecamatan Langowan Barat Kabupaten Minahasa. Jurnal Politico.3(2):1-11.

Peraturan Pemerintah Republik Indonesia Nomor 47 Tahun 2015 tentang Perubahan Atas Peraturan Pemerintah Nomor 43 Tahun 2014 tentang Peraturan Pelaksanaaan Undang-undang Desa Nomor 6 Tahun 2014 tentang Desa

Surono, A. 2017. Peranan Hukum Dalam Pengelolaan Sumber Daya Alam Skala Desa Oleh Badan Usaha Milik Desa (Bumdes) Dalam Meningkatkan Kesejahteraan Masyarakat Desa. Jurnal Rechts Vinding: Media Pembinaan Hukum Nasional. 6(3):459-478.

Tyas, A.S.P. 2017. Identifikasi Kuliner Lokal Indonesia dalam Pembelajaran Bahasa Inggris. Jurnal Pariwisata Terapan. 1(1):1-14. https:/ / doi.org/10.22146/jpt.24970

Undang-Undang Republik Indonesia Nomor 6 Tahun 2014 tentang Desa

Wibowo, H.A., WInarni, F. 2017. Dampak Program P2WKSS terhadap Kesejahteraan Keluarga Miskin di Kelurahan Keparakan, Kecamatan Mergangsan, Kota Yogyakarta. Adinegara. 6(3):263-274.

Widjajanti, K. Model Pemberdayaan Masyarakat. Jurnal Ekonomi Pembangunan: Kajian Masalah Ekonomi 


$$
\begin{aligned}
& \text { dan Pembangunan. 12(1):15-27. } \\
& \text { https://doi.org/10.23917/jep.v12i1.202 }
\end{aligned}
$$

Zanibar, Z. 2007. Desa: Pergulatan Mencari Jati Diri. Jurnal Konstitusi. 4(1):171-196.

Zuliyah, S. 2010. Strategi Pemberdayaan Masyarakat Desa dalam Menunjang Pembangunan Daerah. Journal of Rural and Development. 1(2):151-160. 